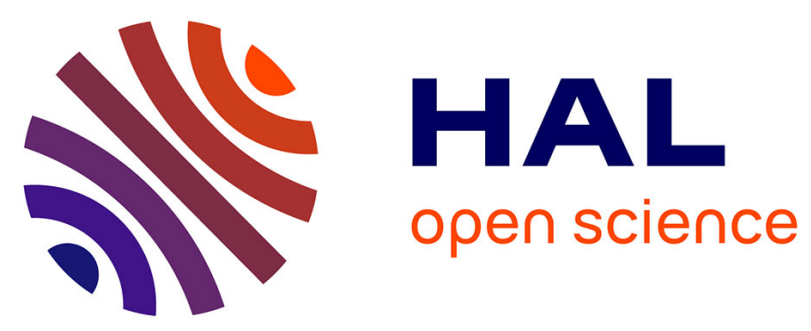

\title{
Co-catalytic oxidative coupling of primary amines to imines using an organic nanotube-gold nanohybrid
}

Dhanaji V. Jawale, Edmond Gravel, Elise Villemin, Nimesh Shah, Valerie

Geertsen, Irishi N. N. Namboothiri, Eric Doris

\section{To cite this version:}

Dhanaji V. Jawale, Edmond Gravel, Elise Villemin, Nimesh Shah, Valerie Geertsen, et al.. Co-catalytic oxidative coupling of primary amines to imines using an organic nanotube-gold nanohybrid. Chemical Communications, 2014, 50 (96), pp.15251-15254. 10.1039/c4cc07951e . hal-01157190

\author{
HAL Id: hal-01157190 \\ https://hal.science/hal-01157190
}

Submitted on 13 Nov 2015

HAL is a multi-disciplinary open access archive for the deposit and dissemination of scientific research documents, whether they are published or not. The documents may come from teaching and research institutions in France or abroad, or from public or private research centers.
L'archive ouverte pluridisciplinaire HAL, est destinée au dépôt et à la diffusion de documents scientifiques de niveau recherche, publiés ou non, émanant des établissements d'enseignement et de recherche français ou étrangers, des laboratoires publics ou privés. 


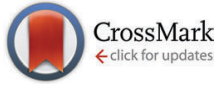

Cite this: Chem. Commun., 2015, 51, 1739

Received 18th November 2014, Accepted 8th December 2014

DOI: $10.1039 / c 4 c c 09192 b$

www.rsc.org/chemcomm

\section{Selective conversion of nitroarenes using a carbon nanotube-ruthenium nanohybrid $\dagger$}

\author{
Dhanaji V. Jawale, ${ }^{a}$ Edmond Gravel, ${ }^{a}$ Caroline Boudet, ${ }^{a}$ Nimesh Shah, \\ Valérie Geertsen, ${ }^{c}$ Haiyan Li, ${ }^{d}$ Irishi N. N. Namboothiri ${ }^{\star b}$ and Eric Doris ${ }^{* a}$
}

Ruthenium nanoparticles were assembled on carbon nanotubes and the resulting nanohybrid was used in the hydrazine-mediated catalytic hydrogenation of various nitroarenes, at room temperature. Depending on the solvent, a selective transformation occurred, giving either access to the corresponding aniline or hydroxylamine derivative.

Substituted anilines and $N$-aryl hydroxylamines are valuable chemicals for the synthesis of pharmaceuticals, agrochemicals, and materials, to cite a few. Anilines can be prepared by direct reduction of nitroarenes under classical reduction conditions or by hydrogenation ${ }^{1}$ over heterogeneous transition metal catalysts. On the other hand, $\mathrm{N}$-aryl hydroxylamines can be obtained by selective reduction of nitroarenes using zinc dust in aqueous $\mathrm{NH}_{4} \mathrm{Cl}$. Other methods include, for example, borohydride reduction ${ }^{3}$ and catalytic hydrogenation. ${ }^{4}$ The main challenge in catalytic hydrogenations is to achieve not only high catalytic activity, but also selectivity towards the nitro group, ${ }^{5}$ especially in the presence of other sensitive moieties. ${ }^{6}$ In addition, hydrogenations of nitroarenes are often run under drastic conditions, requiring high temperatures and/or pressure of hydrogen gas. ${ }^{5,-9}$ To avoid the manipulation of hazardous $\mathrm{H}_{2}$, safer precursors can be used, such as hydrazine monohydrate which stands as a cheap, safe to handle, and convenient source of hydrogen that releases $\mathrm{N}_{2}$ as the only side-product. ${ }^{10-12}$

In this communication, we report the synthesis and characterization of a novel heterogeneous catalyst based on ruthenium nanoparticles (RuNPs) supported on carbon nanotubes (CNTs).

\footnotetext{
${ }^{a}$ CEA, iBiTecS, Service de Chimie Bioorganique et de Marquage, 91191 Gif-sur-Yvette, France.E-mail: eric.doris@cea.fr

${ }^{b}$ Department of Chemistry, Indian Institute of Technology Bombay, Mumbai 400 076, India. E-mail: irishi@chem.iitb.ac.in

${ }^{c}$ CEA, IRAMIS, Nanosciences et Innovation pour les Matériaux, la Biomédecine et l'Energie, UMR3299, 91191 Gif-sur-Yvette, France

${ }^{d}$ State Key Laboratory of Physical Chemistry for Solid Surfaces and National Engineering Laboratory for Green Chemical Productions of Alcohols, Ethers, and Esters, Department of Chemistry, College of Chemistry and Chemical Engineering, Xiamen University, Xiamen 361005, China

$\dagger$ Electronic supplementary information (ESI) available: Experimental details and spectral data for all compounds. See DOI: 10.1039/c4cc09192b
}

The nanohybrid (RuCNT) was applied to the selective reduction of nitroarenes through activation of hydrazine monohydrate under atmospheric pressure and at room temperature.

The CNT-based catalyst was prepared by a layer-by-layer process, extending the scope of a procedure that we previously reported for gold nanoparticles. ${ }^{13}$ In brief, multi-walled carbon nanotubes (Fig. 1a) were sonicated in an alkaline aqueous solution of diacetylene nitrilotriacetic amphiphile DANTA (Fig. 2a).

Van der Waals interactions directed the hydrophobic portion of the amphiphiles to the surface of CNTs while polar heads were oriented towards the aqueous medium. This assembly step gave rise to half-cylinders with nanoring-like structures covering the surface of the CNT (Fig. 1b). ${ }^{14}$ The rings were further stabilized by
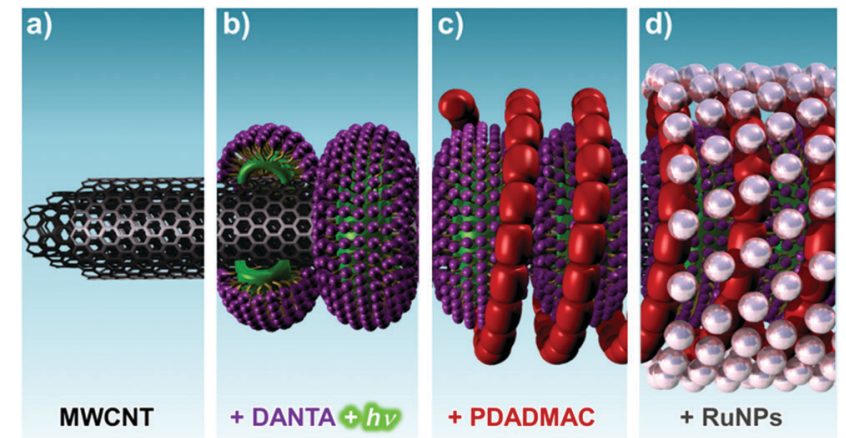

Fig. 1 Layer-by-layer assembly of the RuCNT catalyst: (a) multi-walled carbon nanotube; (b) addition of DANTA and photopolymerization; (c) deposition of the PDADMAC layer; (d) anchoring of RuNPs leading to the final hybrid.

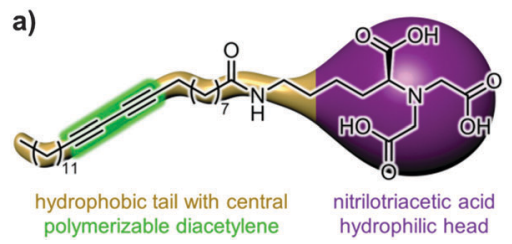

b)

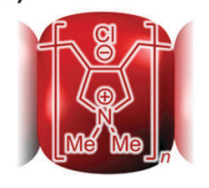

Fig. 2 Structures of (a) DANTA and (b) PDADMAC 
photo-polymerization at $254 \mathrm{~nm}$ of the diacetylene motifs incorporated in the hydrophobic portion of DANTA. ${ }^{15}$ At this point, cationic poly(diallyldimethylammonium chloride) (PDADMAC, Fig. 2b) was added and formed an additional layer (Fig. 1c) as a result of electrostatic interactions with the primary anionic layer. Finally, pre-formed RuNPs ${ }^{16}$ were added to the multi-layer assembly. The metallic nanoparticles were anchored and stabilized within the PDADMAC network (Fig. 1d), owing to the interaction with the ammonium groups. The RuCNT nanohybrid was obtained in aqueous suspension.

The supported catalyst was characterized by transmission electron microscopy (TEM) which confirmed that CNTs were decorated with a dense and homogeneous coating of metal nanoparticles (Fig. 3). Statistical size analysis based on TEM micrographs showed that RuNPs had an average diameter of ca. $2 \mathrm{~nm}$ and inductively coupled plasma mass spectrometry (ICP-MS) indicated that the metal concentration of the RuCNT aqueous suspension was $10 \mathrm{mM}$.

Considering that ruthenium is an active metal for catalytic hydrogenation of nitro groups, ${ }^{7,10,17,18}$ we sought to investigate the potential of our RuCNT nanohybrid for this transformation. Hydrazine monohydrate was selected as a hydrogen source, and 4-bromonitrobenzene (1a) was chosen as a model substrate for the optimization of the reaction conditions (Table 1). We observed that the reduction of 1a proceeded smoothly in the presence of only $0.4 \mathrm{~mol} \%$ of the RuCNT catalyst at room temperature. In addition, we also noticed that the outcome of the reaction was strongly influenced by the nature of the solvents. For example, in methanol (entry 1), 1a was converted into two different products $2 \mathbf{a}$ and $3 \mathbf{3}$, , $48: 52$ ratio). In contrast, only the corresponding aniline $\mathbf{2 a}$ was produced in water (entry 2), and $N$-aryl hydroxylamine $3 \mathbf{a}$ was formed as the sole product when the reaction was carried out in THF (entry 3). The catalytic system was shown to tolerate the presence of oxygen (open flask), although kinetics were less favourable (entries 4 and 5).

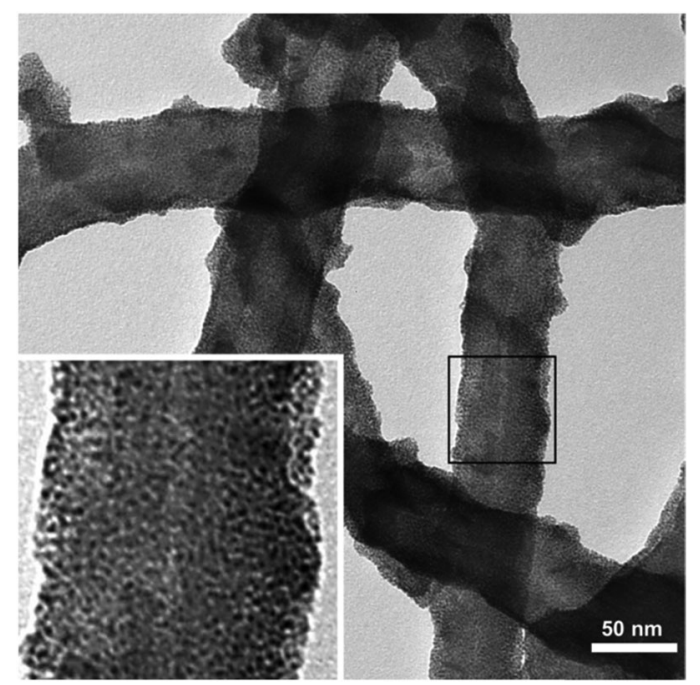

Fig. 3 Transmission electron micrograph of RuCNT. The inset shows a 300\% magnification of the boxed area.
Table 1 Influence of the reaction conditions on the reduction of $1 \mathbf{a}^{a}$

\begin{tabular}{|c|c|c|c|c|c|c|}
\hline & $1 a$ & $\frac{\mathrm{RuCl}}{\mathrm{N}_{2} \mathrm{H}_{4} \cdot \mathrm{r}}$ & $2 a$ & $\mathrm{Br}^{-}$ & & \\
\hline \multirow[b]{2}{*}{ Entry } & \multirow[b]{2}{*}{ Solvent } & \multirow{2}{*}{$\begin{array}{l}\text { Time } \\
\text { (h) }\end{array}$} & \multirow[b]{2}{*}{ Atmosphere } & \multirow{2}{*}{$\begin{array}{l}\text { Ru loading } \\
\text { (mol\%) }\end{array}$} & \multicolumn{2}{|c|}{ Yield $^{b}(\%)$} \\
\hline & & & & & $2 a$ & $3 \mathbf{a}$ \\
\hline 1 & $\mathrm{MeOH}$ & 24 & $\mathrm{~N}_{2}$ & 0.4 & 48 & 52 \\
\hline 2 & $\mathrm{H}_{2} \mathrm{O}$ & 5 & $\mathbf{N}_{2}$ & 0.4 & 98 & - \\
\hline 3 & THF & 2.5 & $\mathbf{N}_{2}$ & 0.4 & - & 98 \\
\hline 4 & $\mathrm{H}_{2} \mathrm{O}$ & 24 & Air & 0.4 & 61 & - \\
\hline 5 & THF & 5 & Air & 0.4 & - & 98 \\
\hline
\end{tabular}

${ }^{a}$ Conditions: 1a $(0.13 \mathrm{mmol})$, RuCNT (0.4 or $\left.0.02 \mathrm{~mol} \%\right)$, hydrazine monohydrate (10 equiv.), solvent $(2 \mathrm{~mL})$, r.t., air or $\mathrm{N}_{2}$ atm. ${ }^{b}$ Isolated yields.

It is worth mentioning that no hydrodehalogenation was observed in the above reactions, highlighting the excellent selectivity of the RuCNT-hydrazine system towards the nitro group. Control experiments carried-out in the presence of hydrazine monohydrate but without RuCNT led to no conversion at all, regardless of the solvent.

To demonstrate that the catalytic process involves a heterogeneous metallic ruthenium species (as opposed to salts that might have leached from the assembly), a reduction reaction of 1a was carried out in THF under the above conditions (Table 1, entry 3) and stopped after $40 \mathrm{~min}$. At this time point, the catalyst was filtered-off and ${ }^{1} \mathrm{H}-\mathrm{NMR}$ analysis of the filtrate indicated $66 \%$ conversion into 3a. The catalyst-free mixture was then stirred for an additional $24 \mathrm{~h}$, but no further conversion was detected.

The catalytic activity of RuCNT was compared to that of $\mathrm{Ru} / \mathrm{C}$, colloidal RuNPs, ruthenium salts precursor to the RuNPs $\left(\mathrm{RuCl}_{3}\right)$, and metal-free multi-layer CNT-assembly (Table 2). The use of colloidal RuNP (entry 3), $\mathrm{RuCl}_{3}$ (entry 4), and metal-free CNTassembly (entry 5) did not give satisfactory conversion under our experimental conditions, either in water or in THF. The only Ru-based system that led to some conversion was $\mathrm{Ru} / \mathrm{C}$, as $95 \%$ of 3a was produced in THF (entry 2) with 0.4 mol\% loading.

Table 2 Comparison of RuCNT with other putatively catalytic species

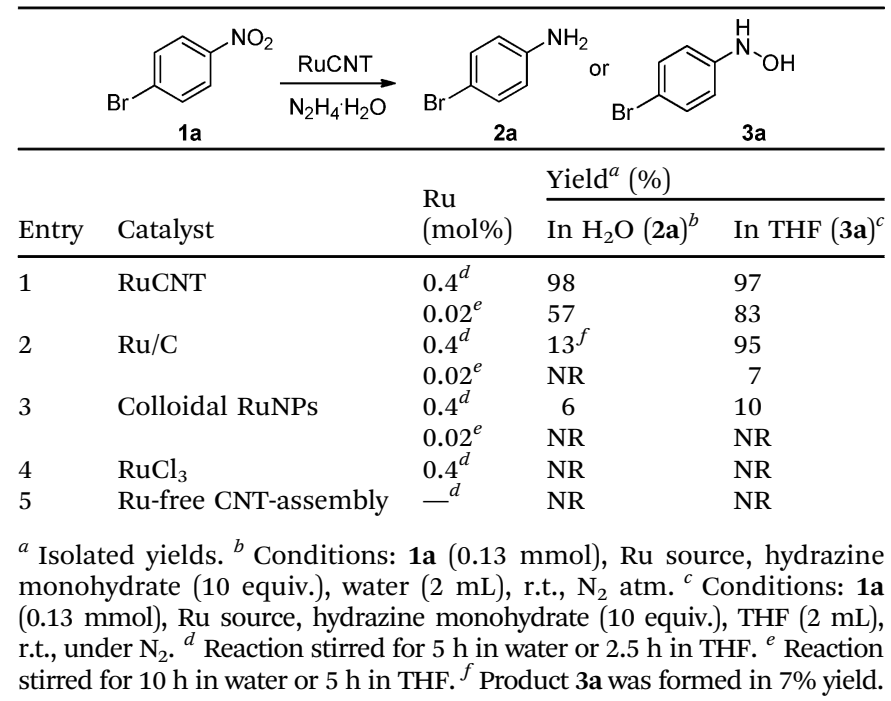


However, $\mathrm{Ru} / \mathrm{C}$ only afforded $\mathbf{2 a}$ in low yield (13\%) when the reaction was run in water. Decreasing catalyst loadings led to obvious differences between RuCNT (entry 1 ) and $\mathrm{Ru} / \mathrm{C}$ as the former catalyst was still highly active whereas the latter became more sluggish, in both solvents. In fact, when the reaction was run with as little as $0.02 \mathrm{~mol} \%$ of the RuCNT catalyst in water, a turnover number (TON) of 2833 and a turnover frequency (TOF) of $283 \mathrm{~h}^{-1}$ were obtained (57\% yield after $10 \mathrm{~h}$ ). In THF, TON and TOF values of 4150 and $830 \mathrm{~h}^{-1}$ were obtained, respectively (83\% yield, $5 \mathrm{~h}$ ). As a comparison, when the same loading of $\mathrm{Ru} / \mathrm{C}$ was used in THF, much lower values were obtained with a TON of 350 and a TOF of $70 \mathrm{~h}^{-1}$ (7\% yield, $5 \mathrm{~h}$ ). The reaction carried out with $0.02 \mathrm{~mol} \%$ of $\mathrm{Ru} / \mathrm{C}$ in water afforded no detectable amount of aniline 2a. These experiments highlight the superiority of our RuCNT nanohybrid catalyst.

One of the advantages of using heterogeneous catalysis is that the catalyst may be recycled and reused, thus reducing the overall cost and environmental impact of the process. To investigate this critical feature, five consecutive reductions of 1a were performed with the same RuCNT sample that was recovered by centrifugation between cycles (for experimental details see the ESI $\dagger$ ). No decrease of the catalytic activity was observed throughout the experiments, regardless of the solvent (96-98\% yield of $2 \mathrm{a}$ in water through 5 cycles of $5 \mathrm{~h}$ each; $95-97 \%$ yield of $3 \mathbf{a}$ in THF through 5 cycles of $2.5 \mathrm{~h}$ each). No ruthenium that might have leached out of the CNT could be detected by ICP-MS analysis of the above reaction mixtures. In addition, TEM analysis of the catalyst after the fifth cycle indicated no morphological alteration except for some occasional bare areas (see Fig. S1, ESI $\dagger$ ). These results substantiate the robustness of the $\mathrm{Ru}$ tethering.

The scope of the process was then evaluated on a variety of nitroarenes, both in water and in THF (Table 3). To confirm that halogen substituents were well tolerated, 4-chloronitrobenzene (1b) and 4-iodonitrobenzene (1c) were engaged in hydrogenation reactions. Both substrates were efficiently converted to either their aniline (2b and $\mathbf{2} \mathbf{c}$ ) or $N$-aryl hydroxylamine (3b and $\mathbf{3} \mathbf{c}$ ) counterparts, depending on the solvent, with no formation of hydrodehalogenation products (entries 1-3). The selectivity of our system was further challenged with the reduction of several substrates bearing reducible functions in addition to the nitro group. Thus, 4-cyanonitrobenzene (1d), 3-nitrostyrene (1e), and 4-nitrophenylacetylene (1f) were engaged in the RuCNT-catalyzed hydrogenation. Compounds 1d-f reacted smoothly and were converted in high yields (i.e. 95-99\%) to the expected products with full selectivity (entries 4-6). To further investigate the potential of our RuCNT catalyst, several substrates including plain nitrobenzene (1g), electron-rich 4-methoxynitrobenzene (1h), and heteroaromatic 2-chloro-5-nitropyridine (1i) were tested. All the investigated nitro-aromatics gave the expected anilines $(\mathbf{2} \mathbf{g}-\mathbf{i})$ when reactions were carried out in water, and the anticipated $N$-aryl hydroxylamines (3g-i) in THF (entries 7-9).

The mechanism behind the observed selective conversion may follow an initial path commonly accepted for the hydrogenation of nitroarenes ${ }^{1,6 d}$ (Scheme 1). For example, nitrobenzene $\mathbf{1 g}$ is sequentially converted to nitroso $\mathbf{1 g}^{\prime}$ and hydroxylamine $\mathbf{3 g}$ in either THF or water. While $\mathbf{3} \mathbf{g}$ was readily reduced in water into the corresponding
Table 3 Scope of the RuCNT-catalyzed reduction of nitroarenes ${ }^{a}$

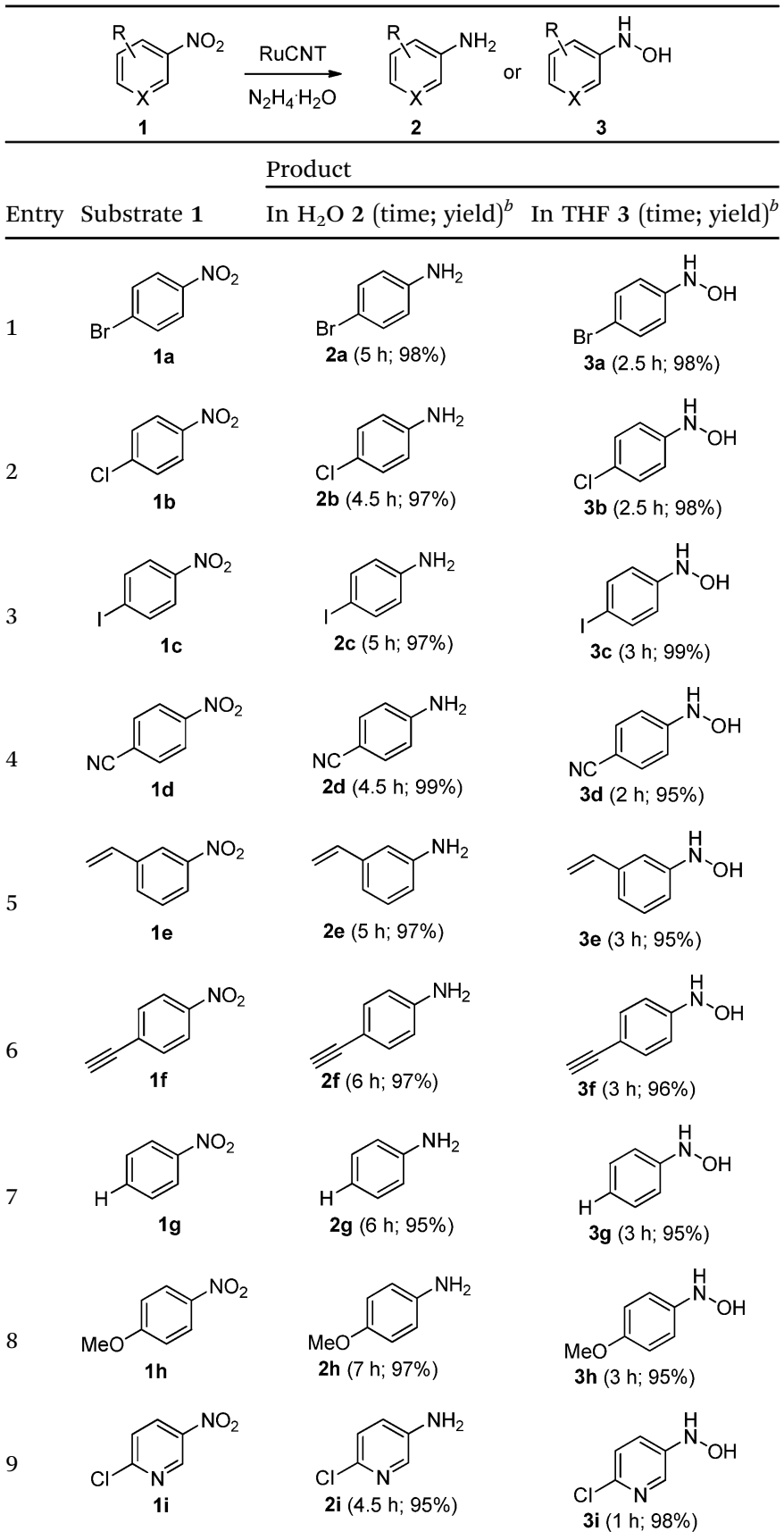

${ }^{a}$ Conditions: 1 ( $\left.0.13 \mathrm{mmol}\right)$, RuCNT $(0.4 \mathrm{~mol} \%)$, hydrazine monohydrate (10 equiv.), solvent $(2 \mathrm{~mL})$, room temp., $\mathrm{N}_{2}$ atm. ${ }^{b}$ Isolated yields.

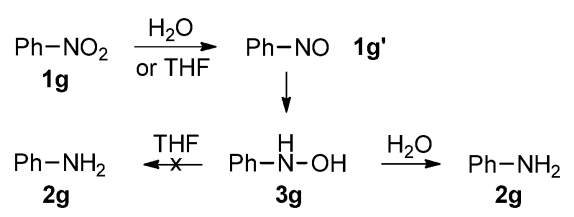

Scheme 1 Postulated mechanism of the selective reduction of nitroarenes.

aniline, it remained unchanged in THF. A control experiment run in THF afforded $3 \mathrm{~g}$ as the only product after $2.5 \mathrm{~h}$. However, upon 
addition of water, $N$-phenyl hydroxylamine $\mathbf{3 g}$ was further converted into aniline $\mathbf{2 g}$. It is to be noted that no selfcondensation products (e.g. azoxy-, azo- or hydrazo-benzene) were detected under our reaction conditions.

Although the exact effect of the solvents on the RuCNT-mediated selective reduction is not fully understood yet, one can hypothesize that specific solvents could affect the adsorbed state of the substrates, hydrogen concentration, and surface concentration of the reactants. Water can also lower the activation energy of the catalytic process, ${ }^{19}$ leading to full reduction of the nitro group. It is however difficult to establish which of these factors predominantly contributes to the observed selectivity.

In summary, a new heterogeneous catalyst was assembled by stabilization of ruthenium nanoparticles on carbon nanotubes. ${ }^{20}$ The nanohybrid was used for the catalytic hydrogenation of various nitroarenes in the presence of hydrazine monohydrate, at room temperature. The system proved very efficient on all the investigated substrates and demonstrated complete selectivity towards the nitro group. Another interesting feature is that the reported catalyst can selectively convert nitroarenes either into the corresponding anilines or $N$-aryl hydroxylamines, depending on the solvent. Both processes are operative under mild conditions and provide excellent yields of the desired products.

Support from the Indo-French Centre for the Promotion of Advanced Research (IFCPAR)/Centre Franco-Indien pour la Promotion de la Recherche Avancée (CEFIPRA) is gratefully acknowledged (Project no. 4705-1). The TEM-team platform (CEA, iBiTec-S) is acknowledged for help with TEM images. The "Service de Chimie Bioorganique et de Marquage" belongs to the Laboratory of Excellence in Research on Medication and Innovative Therapeutics (ANR-10-LABX-0033-LERMIT).

\section{Notes and references}

1 H.-U. Blaser, H. Steiner and M. Studer, ChemCatChem, 2009, 1, 210.

2 For the standard protocol, see: C. S. Marvel and O. Kamm, J. Am. Chem. Soc., 1919, 41, 276. For a modified $\mathrm{NH}_{4} \mathrm{Cl}$-free protocol, see: S. Liu, Y. Wang, J. Jiang and Z. Jin, Green Chem., 2009, 11, 1397.

3 (a) K. Yanada, H. Yamaguchi, H. Meguri and S. Uchida, J. Chem. Soc., Chem. Commun., 1986, 1655; (b) P. Ren, T. Dong and S. Wu,
Synth. Commun., 1997, 27, 1547; (c) P. Ren, X. Pan, Q. Jin and Z. Yao, Synth. Commun., 1997, 27, 3497.

4 K. Taya, Chem. Commun., 1966, 464.

5 A. Corma, P. Serna, P. Concepción and J. J. Calvino, J. Am. Chem. Soc., 2008, 130, 8748.

6 Recent examples include: (a) S. Cai, H. Duan, H. Rong, D. Wang, L. Li, W. He and Y. Li, ACS Catal., 2013, 3, 608; (b) K. Layek, M. L. Kantam, M. Shirai, D. Nishio-Hamane, T. Sasakid and H. Maheswaran, Green Chem., 2012, 14, 3164; (c) H. Zhao, Y. Wang and R. Wang, Chem. Commun., 2014, 50, 10871; For a recent review on platinum-based systems, see; (d) P. Lara and K. Philippot, Catal. Sci. Technol., 2014, 4, 2445.

7 G. Fan, W. Huang and C. Wang, Nanoscale, 2013, 5, 6819.

8 M. Makosch, W.-I. Lin, V. Bumbálek, J. Sá, J. W. Medlin, K. Hungerbühler and J. A. van Bokhoven, ACS Catal., 2012, 2, 2079.

9 M. Takasaki, Y. Motoyama, K. Higashi, S.-H. Yoon, I. Mochida and H. Nagashima, Org. Lett., 2008, 10, 1601.

10 D. Cantillo, M. Baghbanzadeh and C. O. Kappe, Angew. Chem., Int. Ed., 2012, 51, 10190.

11 X. Gu, Z. Sun, S. Wu, W. Qi, H. Wang, X. Xu and D. Su, Chem. Commun., 2013, 49, 10088.

12 S. K. Singh and Q. Xu, Catal. Sci. Technol., 2013, 3, 1889.

13 (a) J. John, E. Gravel, A. Hagège, H. Li, T. Gacoin and E. Doris, Angew. Chem., Int. Ed., 2011, 50, 7533; (b) R. Kumar, E. Gravel, A. Hagège, H. Li, D. V. Jawale, D. Verma, I. N. N. Namboothiri and E. Doris, Nanoscale, 2013, 5, 6491; (c) R. Kumar, E. Gravel, A. Hagège, H. Li, D. Verma, I. N. N. Namboothiri and E. Doris, ChemCatChem, 2013, 5, 3571; (d) D. V. Jawale, E. Gravel, V. Geertsen, H. Li, N. Shah, R. Kumar, J. John, I. N. N. Namboothiri and E. Doris, Tetrahedron, 2014, 70, 6140; (e) N. Shah, E. Gravel, D. V. Jawale, E. Doris and I. N. N. Namboothiri, ChemCatChem, 2014, 6, 2201; $(f)$ D. V. Jawale, E. Gravel, V. Geertsen, H. Li, N. Shah, I. N. N. Namboothiri and E. Doris, ChemCatChem, 2014, 6, 719; $(g)$ N. Shah, E. Gravel, D. V. Jawale, E. Doris and I. N. N. Namboothiri, ChemCatChem, DOI: $10.1002 /$ cctc. 201402782 .

14 (a) C. Richard, F. Balavoine, P. Schultz, T. W. Ebbesen and C. Mioskowski, Science, 2003, 300, 775; (b) N. Khiar, M. P. Leal, R. Baati, C. Ruhlmann, C. Mioskowski, P. Schultz and I. Fernandez, Chem. Commun., 2009, 4121.

15 (a) D. J. Ahn and J.-M. Kim, Acc. Chem. Res., 2008, 41, 805; (b) Y. Okawa and M. Aono, J. Chem. Phys., 2001, 115, 2317.

16 Y. Wang, J. Ren, K. Deng, L. Gui and Y. Tang, Chem. Mater., 2000, 12, 1622 .

17 A. I. Carrillo, K. G. Stamplecoskie, M. L. Marin and J. C. Scaiano, Catal. Sci. Technol., 2014, 4, 1989.

18 M. Oubenali, G. Vanucci, B. Machado, M. Kacimi, M. Ziyad, J. Faria, A. Raspolli-Galetti and P. Serp, ChemSusChem, 2011, 4, 950.

19 B. S. Akpa, C. D’Agostino, L. F. Gladden, K. Hindle, H. Manyar, J. McGregor, R. Li, M. Neurock, N. Sinha, E. H. Stitt, D. Weber, J. A. Zeitler and D. W. Rooney, J. Catal., 2012, 289, 30.

20 For a recent review on CNT-supported catalysts, see: J. John, E. Gravel, I. Namboothiri and E. Doris, Nanotechnol. Rev., 2012, 1, 515. 